\title{
Specific Embodiment of Heavy Industrial Waste in the Urban Landscape
}

\author{
Yijie Liu ${ }^{1}$, Xiaoqing Zhao ${ }^{2}$ \\ ${ }^{1}$ Department of Art and Design, College of Art and Design, Wuhan University of Science and \\ Technology, Wuhan, Hubei Province, Post code: 430081; \\ ${ }^{2}$ Wuhan University of Science and Technology, Wuhan, Hubei Province, Post code: 430081
}

\begin{abstract}
Wuhan, with a complete industrial system including steel, automobile and shipbuilding industry, is the biggest industrial and commercial city in central China, as well as a industrial city with state key construction. Wuhan Iron and Steel Corporation is taken as an important representative here, which Wuhan people were honored and proud of. However, environment pollution follows industrial prosperity. In the new century, the paper is to give new life to the representative of Wuhan - waste iron and steel and residue in the form of artistic creation upon the graduation design to better develop the economy of Wuhan and present spiritual outlook of Wuhan. It is expected to turn Gongye 4th Road into an artistic zone about waste iron and steel and make the idea of environment protection strike root in the hearts of the people.

The materials - waste iron and steel and residue are processed with art creation and then applied in spatial landscape design, specifically in landscape such as road, greenbelt and square.

Design includes "home of artists" and "exhibition park". "Home of artists" is an art center reconstructed from original old factory, which combines artistic creation and life to make it serve as a park of artists. In order to better display artistic works, the green areas in park are designed and transformed into theme sculpture parks. The distance between the art of waste iron and steel and the general public is supposed to be shortened.

In today's worsening ecological environment, the paper is designed in order to give new life to waste iron and steel in the form of artistic creation rather than recycle in a simply way, create higher value, and create street space full of artistic elements, so as to show the diversity of iron and steel industrial city.
\end{abstract}

Keywords: Scrap steel; Waste soil; Creations; Environmental protection; Industrial landscape

\section{重工业废旧物在城市景观中的特殊体现}

\author{
刘艺洁 ${ }^{1}$, 赵晓晴 ${ }^{2}$
}

(1.武汉科技大学艺术与设计学院, 艺术设计系, 湖北省武汉市, 邮编; 430081，2. 武汉科技大学, 湖北省 武汉市，邮编 430081)

摘要: 武汉是华中地区最大的工业、商业城市, 也是国家重点建设的工业城市，拥有钢铁、汽车、造船、等完整的工 业体系。这其中以武钢为重要代表, 它一度成为武汉人心中的骄傲和自豪。但是工业繁盛的背后是环境的污染。在新的世纪 中, 为了更好的发展武汉经济和展现武汉精神面貌, 利用本次毕业设计的机会, 决定以武汉的代表性——废旧钢铁和废渣为 载体用艺术创作的形式来赋予其新的生命。把工业四路打造成有关于废旧钢铁的艺术区，使环保的理念深入人心。

设计的范围包括“艺术师之家”和“展览公园”。”艺术师之家”是利用原本的旧厂区改造成艺术中心，里面集艺术创作、生 活一体, 使之成为艺术家们的乐园。为了更好地展示艺术作品, 还利用原有的公园绿化区域, 设计改造成了主题性雕塑公园。 希望可以拉近废旧钢铁艺术与普通大众的距离。

这次设计希望在环境恶化的今天, 使废旧钢铁不再单单简单的回收利用, 而是想用艺术加工创作的手法来赋予新的生命, 创造更好更高的价值，创造充满艺术元素的街道空间，展示钢铁工业城市的丰富多彩一面。

关键词: 废钢铁; 废渣土; 艺术创作; 环保; 工业景观 


\section{引言}

1785 年詹姆斯・瓦特改造的蒸气机开创了新的产业革命并将人类推进到工业文明。物质财富极大的 增加, 社会文化也随之改变, 即工业文化。在这个大的背景下, 表现工业文化的城市景观既称为工业景观, 也包括那些虽不以表现工业文化为设计初衷, 但是景观元素的外在性质却带有鲜明的工业文化特征, 观赏 者从中可以或欣赏、或理解、或怀念、或感悟……业文化的城市景观。随着工业化程度的不断加剧, 工 业化促进了城市化, 产生了很多城市问题, 城市工业废弃地的出现也促生了众多的城市后工业景观重建项 目。按照对象的不同和尺度的大小，大致可分为后工业城市再生、工业遗产的保护与再利用、旧工业建筑 的再利用 (创意产业园模式)、后工业景观设计等, 涉及到的学科包括城市规划与设计、遗产保护、建筑设 计、景观设计和环境艺术等。工业景观的研究始于 1960 年左右, 随着社会的发展, 原有的一些工业设施 被废弃并拆除, 导致工业区渐渐地失去了往日的活力而面临着衰败。一些有识之士意识到作为人类历史发 展过程中重要环节的工业文化应该予以保留, 而且受到同一时期兴起的城市中心复兴运动的影响, 大量的 工业建筑和设施被改造再利用。国外在该领域已经取得了显著成果, 如美国西雅图炼油厂改造、英国伦敦 码头更新、法国洛林区更新等。特别是在工业化发展比较成熟的德国, 以鲁尔工业区的更新建设为代表, 自 1980 年以后, 建成了一大批优秀的工业景观。国内的工业景观建设起步较晚, 在 1990 年代后期才有所 建设, 实例有广东中山岐江公园、北京 798 艺术工厂等。

\section{1 价值分析}

旧有的工业景观曾经在工业型城市中占有重要的地位。20世纪后期, 许多旧有工业景观失去了原有的 物质功能而被长期空置、废弃。成为城市环境建设的负担。针对这种状况, 对于旧有工业景观的内在价值 面临着重新定位和再次挖掘。

首先，旧有的工业景观中蕴含着巨大大的文化价值。旧有工业景观曾是一个时期新技术、新材料、新 结构的代表, 是城市完整形象和历史沿革的见证。也承载着人们对于特定历史年代的记忆。许多工业景观 的元素如厂房、烟图、高炉等形象。已深深地印在几代人的脑海里, 它们既是历史的见证人又承载着人们 的情感。

其次，旧有工业景观更新再利用有着巨大的经济价值。更新再利用就使蕴含在其中的经济价值得到再 次释放并投入到新的作品中。而且还有可能挖掘出更大的经济文化价值, 其产生的经济文化价值是无法估 量的。例如，旧厂房由于大空间的特征很容易被改建为其他功能的建筑。

第三，旧有工业景观更新在利用也增加了大量就业机会，包括工程技术、运营维护、服务配套等相关 产业的就业人群。伴随着就有工业景观更新再利用而进行的产业结构调整, 也就促进了新建工业景观的建 设。这样, 工业景观的建设就更加满足了人们物质和精神的需求, 同时, 优秀的工业景观建设也刺激和完 善社会各个方面的进步和发展。所以旧工业景观的建设与更新有着巨大的经济与文化价值, 这也是本次毕 业设计的出发点和立足点。

\section{2 旧有工业区更新再利用遵循的原则}

首先是尊重文脉。表现地块所独有的工业文化，是居民产生归属感和认同感。同时注重对原有景观元 素的尊重和理解, 有选择的保留能表现工业文化含义的景观元素, 使其具有鲜明的工业文化特色。关注抽 
象景观概念的物质文化转化, 如加工业发展过程, 工业历史的重大事件。通过以系列活动使其具有鲜明的 工业文化特色。关注抽象景观概念的物质转化, 如工业发展过程, 工业历史的重大事件等。通过一系列活 动使现在的人们能够对原来的工业文化有所认识和理解，例如工业旅游。工业体验等活动。

其次是注重可持续发展。对由于工业化生产而被破坏的的自然环境进行生态恢复，对其改善土壤、水、 植被、空气等而使环境得到恢复。发展的内涵不再局限与单纯的经济增长和技术进步, 而是把它理解成社 会经济、政治、文化各个子系统的相互协调和促进，以及人们生活方式。旧有工业景观更新再利用就是在 传承以往辉煌的工业文化的同时。对社会物质资源的循环利用和社会精神财富的传承与发展。特别是关注 人的发展水平, 保证足够的开放空间, 满足人们的不同使用要求。在人们过去的观念中, 生锈的机器, 残 破的厂房, 焦黑的土壤, 刺鼻的空气……, 这些是不会与美好的景观联系在一起的。但是旧有工业景观工程 实例为人们展示了在这样的地段建造美好景观的可行性, 开拓了人们认识工业美的境界, 提升了人们对景 观美学的鉴赏力。

\section{3 旧有工业景观更新再利用主要表现为三种模式}

\section{1 工业景观公园模式}

这类公园大多以一个大型废弃的工厂为基地, 景观元素带有明显的工业化痕迹, 但是为游人提供了游 乐和休䪹的很多活动场所。作为整体来讲, 是一种全新的景观公园类型一工业景观公园, 如杜伊斯堡北 公园和杜伊斯堡内港公园。

\section{2 文化中心模式}

利用原有的工业景观元素包括工业厂房、工业构筑物、机器等物质设施进行展示并发掘其中的工业文 化内涵, 通过原来工人的讲述或对原有工业生产等一系列特色活动的再现, 改造成为博物馆、会议中心或 图书馆等形式，使人们对工业文化历史的发展和辉煌有深刻地和直观地了解和感悟。

\section{3 商业购物模式}

这类利用都是在城市中心，工业厂房空间较为容易适合现代零售业的需要，加之在城市中，能够吸引 大量的顾客。这种运营模式不仅仅是买卖的活动，还包含了许多娱乐休闲的活动，如柏林旧工厂改造的商 业中心就包含了餐厅、酒吧、电影院等多种功能怛。

新建工业景观的建设趋势在当今的后工业社会中, 原有的工业景观营造理念和技术已经不能很好地适 应新的工业发展, 采取什么样的模式来进行建造仍在探索之中。这里讨论的新建工业景观是指建设在衰败 工业地块上的新景观, 它对于工业地块的复苏和振兴具有积极的意义。通过对当前德国新建工业景观的考 察和研究, 大致分为两种趋势, 即生产型工业景观和科研型工业景观。生产型工业景观以工业生产为目的, 但适应了现代社会的需要，尤其是考虑了工人的使用要求。与环境能够和谐相处，并将自身的企业文化融 入其中以提升企业的社会形象。形态特征大多规模宏。

\section{4 设计原则与方法}

首先，表现工业文化。对于不同的地块应表现的工业文化内容也不尽相同，这是对当地的工业文化的 诠释与表现。在位于武汉市的工业四路附属地块设计中巨大的废旧工业厂房是其设计重点。借助这个巨大 体量的形式表现了该地区曾经辉煌的工业。

其次，遵循了 “人性化” 的设计原则。不仅仅是表现在物质化的景观元素，包括残疾人通道、水池、 
绿化、座椅等等, 更为值得借鉴的是概念上的 “人性化” 设计, 以及如日照质量、温湿度的测评、空气 质量等物理化学环境的测量和评估。

第三，注重生态的理念。尽量使用太阳能、风能等可再生能源或者废弃能源的再利用以及提高能源的 利用效率; 尽量使用可循环使用的建筑材料; 强调适宜技术的使用。利用原有场地的黑色矿石作为室内蓄 能材料, 白天吸收太阳的热量到晚上渐渐散发出来, 这样的设计既表现了场所的特征又起到了良好的生态 效应。

\section{5 设计方法分析}

\section{1 方法分析}

在设计中, 绿化是重要的一环。一方面是作为基础绿化需求, 绿化种植具有一般场所绿化功能的普遍 意义, 但项目地点在重工业区, 化工污染很严重, 绿化可以在一定程度上减轻污染。另一方面是位于雕 塑公园的树阵和立体绿化, 在满足生态效益的前提下侧重视觉的需求, 设计树阵于灯阵结合的景观, 在景 观平台上进行立体绿化既增加了绿化面积又美观了景观。

景观小品层，在进行设计时主导原则是参与性和实用性。人最常经过的地方，人流最易密集的地方提 供小品景观和座椅, 有人存在的地方要有景观。小品一方面能够与功能相结合另一方面要满足视觉的需要。 景观平台的景观主要注重可观性, 趣味性。符合其主题的需要。

铺装层, 铺装层主要分为两块区域: 一是艺术师之家广场的地面铺装, 主要采用煤渣土砖地铺面, 符 合景观的特点。二是雕塑公园广场的铺装采用的是工业特色钢板, 使入口前景和后面平台风格统一, 融会 贯通。三是在工业四路的铺装采用的是沥青混凝土, 是道路与其他两处景观相融合, 真正的做到其连接两 处的 “桥梁”。

\section{2 区域分析}

\subsection{1 艺术师之家既工厂改造区}

本块区域是工业四路原有的一块旧工厂区，本地块中，包含一座建材市场、武钢附属工厂等企业。房 屋多为工业厂房, 在体积面积上都比较大且空间感也很强。但是绿化面积少, 植被稀疏且单一, 生态上无 多样性可言。周边环境多为居民区, 做为工业用地, 其与周边环境是格格不入的。在改造设计中,

首先入口是一个大面积的广场空间, 铺装是煤渣土砖, 颜色上采用了红白色, 给人以强烈的视觉冲击。 在砖的铺设上, 设计成白砖呈不规则的线把广场分割成不规则的块, 为了不使广场显得空旷和单调, 在地 块中覆土种植植物, 植物的选择上是其高大的乔木。开阔的广场上只有零星的几棵树, 就是为了在这么大 的广场面中, 达到某种平衡。

其次艺术师之家中的生活区中, 是在原有建材市场的建筑基础上改建而成的。设计保留了左右两边的 建筑, 而单独把中间的两座建筑给去掉, 去掉的区域则设计成了一个小型花园。是供人游玩与休闲的主要 场所, 在花园的设计思想中, 是人与自然的和谐共处, 与钢铁的完美结合。这是柔与刚的结和, 花园中的 植物与头顶的钢脚架正是这两者的体现。

第三就餐区的设计基础是两座废旧的厂房, 为了与周边环境相呼应, 也是与主题相呼应。在废旧厂房 的外墙立面上没有追求豪华, 而是包留了简单朴素的一面, 红砖灰瓦给人以无限的避想空间。就餐区分为 室外、室内两种, 在室外的设计中紧邻着前门广场, 这样经营范围即可对外, 又可对内。在小的细节中处 
处体现着废旧钢铁的再利用, 扶手、喷泉池、座椅等等。

第四是室外体验与展览区中, 其设计载体是一块大面的草坪, 在草坪中设置了一些废旧的炼钢设备, 这些设备已经成为整个园内最重要的室外展示艺术品。它是整个园内的艺术灵魂, 也成为园内最吸引人流 的地方。

\section{2 .2 雕塑公园}

本块区域是工业四路原有的一个游园, 游园连接工业一路、二路、三路, 是整个大型社区的重要绿化 带。但是游园内部缺乏管理, 导致植物品种单一其生长也不是很好, 游园内基本无人去游玩。

首先是雕塑公园的广场, 起地面铺装是石材与钢铁的结合, 使入口前景和后面平台风格统一, 融会贯 通。在植物的种植上, 也是才用了零星种植的方式和树阵的方式, 这两种方式看似矛盾, 但也互相呼应

其次公园的另一半是纯私密区, 大面积种植了树木, 地面路径是不规则的, 这就形成许许多多的地块, 在这些地块中覆煤渣土种植植被, 形成树下空间。这也与另一半的开敞广场想成了强烈的对比, 一开阔空 间，而另一个是私密空间。两者造就了雕塑公园其柔与刚的结合。这也正好符合其设计理念。

\section{6 设计目的及意义}

以废旧钢铁和废渣为素材和创作原料, 进行其艺术加工, 把其运用在空间景观的设计中, 具体的用在 道路、绿地、广场等景观区域中。

设计的范围包括 “艺术师之家” 和 “展览公园”。”艺术师之家” 是利用原本的旧厂区改造成艺术中 心, 里面集艺术创作、生活一体, 使之成为艺术家们的乐园。为了更好地展示艺术作品, 还利用原有的公 园绿化区域, 设计改造成了主题性雕塑公园。希望可以拉近废旧钢铁艺术与普通大众的距离。这次设计希 望在环境恶化的今天, 使废旧钢铁不再单单简单的回收利用, 而是想用艺术加工创作的手法来赋予新的生 命, 创造更好更高的价值, 创造充满艺术元素的街道空间, 展示钢铁工业城市的丰富多彩一面。

\section{7 致谢}

此论文由教育厅人文社科课题, 工业固体废弃物在园林景观中的应用 $16 Y 020$ 支持

\section{8 结论}

工业文明时期的工业场地、工业景观是工业生产的物化表征和驱动社会经济发展的载体，是地区经济 辉煌的标志。如果将其比作生态元, 它是符合现实生态位的空间和功能要求的。但当结构性危机产生以后, 工业场地逐渐转化为工业废弃地, 工业景观也演变成了废弃工业设施, 表明它的现实状态已经与原来的生 态位置不符; 而工业景观公园作为工业废弃地更新的一种成功对策, 实质上是探寻到了与新的环境条件相 符合的潜在生态位置, 占据并充分利用资源将潜在生态位转化成新的现实生态。公园的设计和营造包含了 生态演化进程, 因此不应该是一蹴而就、生硬地景观处理, 而应是展现长期的循序渐进的自然演化过程, 例如金属广场铁板的持续腐蚀、受污染土壤上植被的生长等。其中也包括规划设计工作的不断修正和完善。

目前，工业废弃地的再生问题是我国大量资源型城市、老工业基地必须面对并亟待解决的问题。北杜 伊斯堡景观公园作为后工业景观公园的经典范例, 对国内工业废弃地改造利用的理论研究与实践探索具有 重要的借鉴意义。但我们应该看到, 这一案例的成功是基于其特定的社会发展阶段和技术、经济背景, 对 手我国现状条件下的工业废弃地而言, 建设后工业景观公园是否具备条件, 应采取怎样的设计方法、实施 
过程和运营模式，尚需要依据客观的分析研究做出慎重、科学的解析与求证。

参考文献:

[1] 王向荣, 任京燕. 从工业废弃地到绿色公园--景观设计与工业废弃地的更新 [期刊论文]-中国园林 2003 (3)

[2］冯春萍．德国鲁尔工业区持续发展的成功经验[期刊论文]-石油化工技术经济 2003(2)

[3] 期刊论文. 张静, 丁奇. ZHANG 后工业景观内涵的比较与思考 -南京林业大学学报（人文社会科学版）2007, 7 (2)

[4] 学位论文. 李建斌. 沈阳市工业景观更新与设计研究——与德国城市工业景观更新与设计的研究比较 2005

[5] 期刊论文. 张艳锋, 张明皓, 陈伯超. 老工业区改造过程中工业景观的更新与改造

——沈阳铁西工业区改造新课题 现代城市研究 2004, 19(11)

[6]会议论文. 孙艺松. 哈尔滨市老工业区资源环境再利用研究 2007

[7] 学位论文. 贾静. 城市工业遗迹保护与园林环境更新——沈阳铁西工业文化长廊的营造 2005

[8］魏风巢．上海石化总厂地区环保型人工植物群落及其功能的探讨 $[J]$ ．生态园林论文续集，1993，129-139。

[9］王克勤，赵瑗，等．园林生态城市一城市可持续发展的理想模式 $[J]$ ．浙江林学院学报，2002 (1) .

[10］陈自新．城市园林绿化与城市可持续发展 [J] . 中国园林，1998，14(5)：4-5.

\section{References:}

[1] Wang Xiangrong, Ren Jingyan. From Industrial Wasteland to Green Park-Landscape Design and Update of Industrial Wasteland [Journal]-Chinese Landscape Architecture,2003(3)

[2] Feng Chunping. Successful Experience of Sustainable Development in Germany's Ruhr Industrial Area [Journal]-Techno-Economics in Petrochemicals,2003(2)

[3] Journal papers. Zhang Jing, Ding Qi. Comparison and Thinking on connotation of Industrial Landscape after ZHANG-Journal of Nanjing Forestry University (Humanities and Social Sciences Edition),2007,7(2)

[4] Thesis. Li Jianbin. Industrial Landscape Update and Design Research in Shenyang-Study on Comparison of Renewed Urban Industrial Landscape in Germany, 2005

[5] Journal papers. Zhang Yanfeng, Zhang Minghao, Chen Bochao. Renewal and Transformation of Industrial Landscape in Process of Transforming Old Industrial Area-Modern Urban Studies on Transformation New Problem in Shenyang Tiexi Industrial Area, 2004,19(11)

[6] Conference papers. Sun Yisong. Study on Reuse of Old Industrial Areas, Resources and Environment in Harbin City, 2007

[7] Thesis. Jia Jing. Protection and Updating of Landscape Environment of Urban Industrial Sites-Construction of Shenyang Tiexi Industrial Culture Gallery,2005

[8] Wei Fengchao. Research on Community and Its Function of Environmental Artificial Plant Community in Shanghai Petrochemical Area [J].Sequel to Ecological Gardening Articles, 1993, 129-139.

[9] Wang Keqin, Zhao Yuan,etc. Landscape Ecological City-Ideal Model of Sustainable Urban Development [J].Journal of Zhejiang Forestry College,2002(1)

[10]Chen Zixin. Urban Greening and Urban Sustainable Development [J].Chinese Landscape Architecture, 1998, 14(5):4-5. 